\title{
Ewing's Sarcoma of the Cranial Vault Revealed by Macrocrania
}

\author{
Abdoulaye Diop ${ }^{1}$ Lamine Thiam² ${ }^{2}$ Mohameth Faye ${ }^{3}$ Fabrice Senghor ${ }^{4}$ Momar Codé $\mathrm{Ba}^{3}$ \\ Seydou Boubacar Badiane ${ }^{3}$
}

${ }^{1}$ Neurosurgery Unit, Ziguinchor Peace Hospital, Ziguinchor, Senegal

${ }^{2}$ Pediatrics Department, Ziguinchor Peace Hospital, Ziguinchor,

Address for correspondence Abdoulaye Diop, Assane Seck University, Senegal

${ }^{3}$ Neurosurgery Department, Fann Teaching Hospital, Dakar, Senegal

${ }^{4}$ Anatomical Pathology, Unit Peace Hospital of Ziguinchor,

Ziguinchor, Senegal

Asian J Oncol 2021;8:57-59.

\begin{abstract}
Keywords

- Ewing's sarcoma

- cranial vault

- macrocrania

Ewing's sarcomas are a heterogeneous group of aggressive tumors affecting mostly children and young adults. They account for $10 \%$ of primary malignancies of the bones and $3 \%$ of all malignancies in children. They mainly affect the long bones, pelvis, and ribs. Cranial vault localization is extremely rare and indeed account for less than $1 \%$ of all localizations in the body. We are reporting the unusual case of a 3-year-old child who presented to our unit with a macrocrania which had been evolving for 2 months prior to his admission, associated with sporadic vomiting and a right frontal swelling that was gradually installed. The cerebral computed tomography scan showed a right frontoparietal lytic tissular process, heterogeneously enhanced after injection of contrast material; with dural invasion and intraparenchymal extension. The child was biopsied and the pathological examination concluded Ewing's sarcoma. The evolution was fatal with the passing of the child 2 weeks after the biopsy.
\end{abstract}

\section{Introduction}

Ewing's sarcoma is the second most prevalent bone tumor in children after osteosarcoma. ${ }^{1}$ It belongs to a large family of small blue round cell tumors. Ninety percent of these sarcomas occur in the first or second decade of life. ${ }^{2}$ The most affected sites are long bones, ribs, and the pelvic belt. ${ }^{3,4}$ The cranial vault is rarely affected, representing $1 \%$ of all sites. ${ }^{1,5}$ The symptomatology is usually atypical and nonspecific. We are reporting an unusual case of macrocrania revealing a Ewing's sarcoma of the cranial vault, with dural invasion and intracerebral extension in a 3-year-old child.

\section{Case Report}

The patient was a 3-year-old boy with no notable pathological history. He presented to our unit with a macrocrania ( - Fig. 1) which had been evolving for 2 months prior to his admission and sporadic vomiting. Neurological examination showed altered consciousness with a Glasgow Coma Scale rated to 12 (E3M5V4), an intracranial hypertension syndrome, and a proportional left hemiparesis. The examination of the cephalic extremity showed a macrocrania with a cranial perimeter of $65 \mathrm{~cm}$ and a right frontal swelling, fixed to the vault of the skull, long axis measuring $40 \mathrm{~mm}$, with a healthy skin above. The child was also clinically anemic and severely malnourished. The rest of the clinical examination was within normal limits. The brain computed tomography (CT) scan ( - Fig. 2) showed a right frontoparietal lytic tissular process which was heterogeneously enhanced after injection of contrast material. It has a bilateral hemispherical endocranial extension mainly in the extradural area, as well as dural invasion, intraparenchymal extension with significant perilesional edema. published online

May 31, 2020
DOI https://doi.org/

$10.1055 / \mathrm{s}-0040-1713318$

ISSN 2454-6798. (c) 2020. Spring Hope Cancer Foundation \& Young Oncologist Group of Asia. This is an open access article published by Thieme under the terms of the Creative Commons Attribution-NonDerivative-NonCommercial-License, permitting copying and reproduction so long as the original work is given appropriate credit. Contents may not be used for commercial purposes, or adapted, remixed, transformed or built upon. (https://creativecommons.org/licenses/by-nc-nd/4.0/).

Thieme Medical and Scientific Publishers Pvt. Ltd. A-12, 2nd Floor, Sector 2, Noida-201301 UP, India 
This exerts a mass effect on the lateral ventricles which made them collapse, and also on the midline which deviated to the left. The process seemed to originate from the vault which was lysed, along with infiltration of the soft tissues.

Chest, pelvis, and both femurs X-rays and abdominal ultrasound were performed as a part of workup for extension and returned normal. The child was biopsied using a paramedian frontal approach focused on the swelling. While operating, we found out a grayish fleshy and very hemorrhagic tumor with a completely eroded frontal bone. We collected samples of the eroded bone as well as the invaded dura mater. Anatomopathological examination confirmed Ewing's sarcoma with a proliferation of small round cells of compact layered architecture with slight neovascularization of the sinusoid type ( - Fig. 3). The evolution was fatal, with the passing of the child during hospitalization, 2 weeks after the biopsy.

\section{Discussion}

Described in 1921 by James Ewing, Ewing's sarcoma is the most common primary malignant bone tumor after osteosarcoma in young people. ${ }^{1}$ In $90 \%$ of cases it occurs in the first or second decade of life with a slight male predominance. ${ }^{1,2}$ These

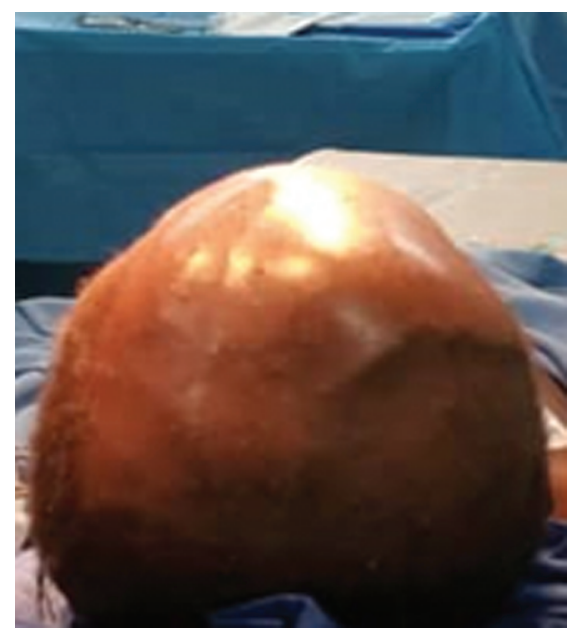

Fig. 1 Macrocrania with right frontal swelling (preoperative). tumors mostly involve the long bones, pelvis, or ribs. ${ }^{3}$ Primary cranial localization is rare and accounts for only $1 \%$ of sites. ${ }^{1,5}$ Pritchard et al found only 3 cranial cases out of $229 .{ }^{6}$ However, the frontoparietal location described in our study is the most frequently found in the literature. ${ }^{5}$

The symptomatology is usually atypical and nonspecific, as symptoms appear depending on dural invasion, hydrocephalus, or increased intracranial pressure. It is the localized swelling of the arch that catches attention. ${ }^{7}$ It rapidly evolves, and is attached to the bone, as in our case. The signs of intracranial hypertension and motor deficit found in our patient seemed to be related to the volume of the tumor and its intracranial extension. No cases of Ewing's sarcoma with endocranial extension revealed by macrocrania have ever been reported in the literature. The pattern of a secondary and progressive macrocrania in children related to a tumor process remains that of the choroid plexus papilloma. However, any supra- or subtentorial tumor can induce intracranial hypertension with progressive macrocranial involvement. ${ }^{8}$

The bone window cerebral CT scan remains the gold standard examination, and allows a better analysis of bone lesions as well as intra- and extracranial extension. ${ }^{1,2}$ Our patient had a large tumor with bilateral hemispherical endocranial extension mainly in the extradural area, which may be confused with an epidural hematoma. This multifocal extradural intracranial location has been described by Wang and Guo. ${ }^{9}$

Ewing's sarcoma is a highly aggressive and rapidly metastatic tumor. ${ }^{10}$ However, early metastases are less common in primary Ewing's sarcoma, so cranial localizations are considered to have a better prognosis. ${ }^{11,12}$ Unlike what has been reported in the literature, the evolution of our patient was fatal due to the size of the tumor and its intracranial invasion. The extent of the endocranial invasion and the soft tissue of the tumor made it impossible to perform total or partial excisional surgery in that case. Chemotherapy and radiotherapy are the treatment of choice in inoperable cases. Our patient passed away long before the histological confirmation of the diagnosis, and thus, could not benefit from further treatment.

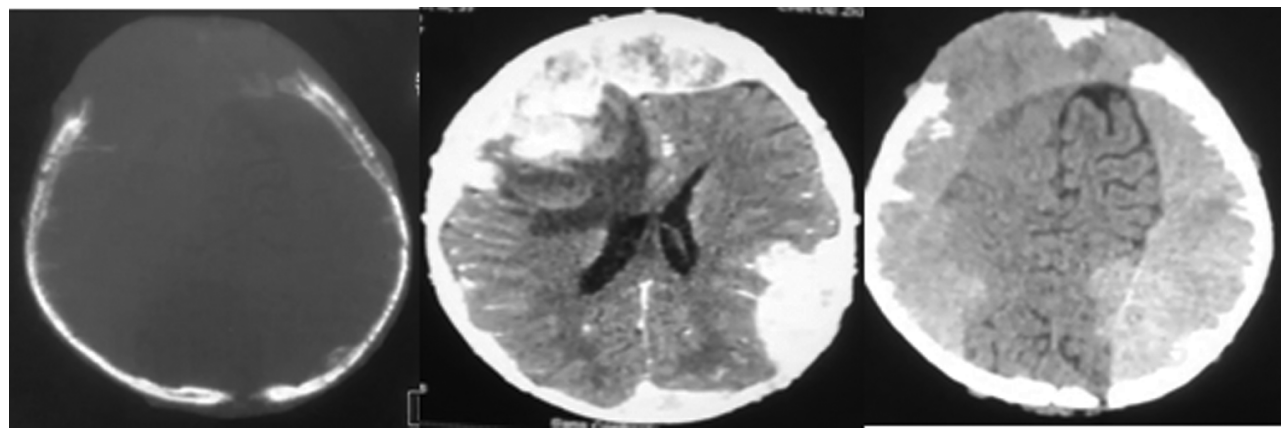

Fig. 2 Cerebral computed tomography scan showing a lytic, right frontoparietal tissular process heterogeneously enhanced after injection of contrast material with bilateral hemispherical predominantly extradural endocranial extension with dural invasion and intraparenchymal extension and significant perilesional edema. 


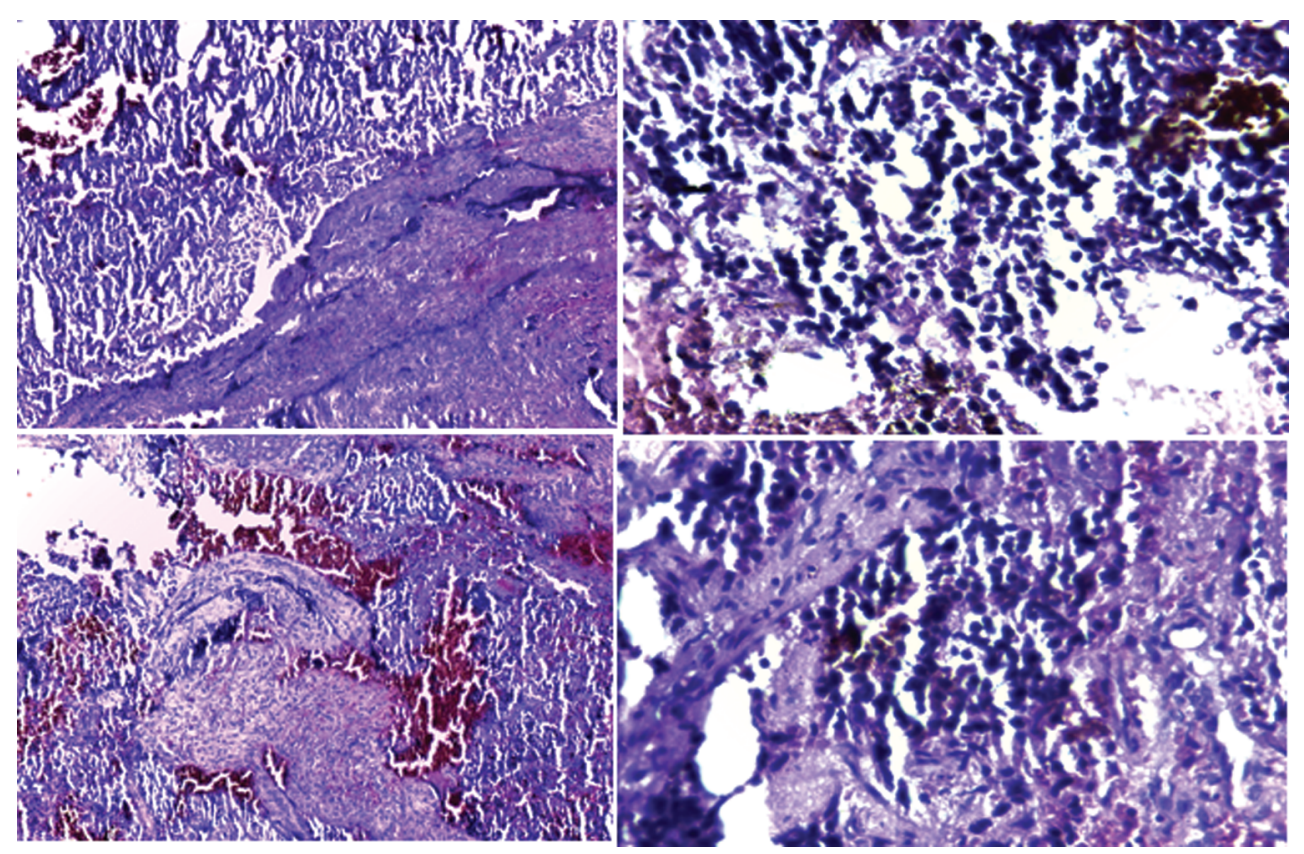

Fig. 3 Proliferation of small round cells into compact sheet architecture with slight sinusoid-like neovascularization.

\section{Conclusion}

Ewing's sarcoma is a malignant bone tumor of the young subject. Primary localization at the vault of the skull is rare. The signs are mostly atypical and nonspecific. However, macrocrania as a circumstance of discovery of the primitive localization of the sarcoma of the cranial vault is exceptional.

\section{Conflict of Interest}

None declared.

\section{References}

1 Bricha M, Jroundi L, Boujida N, El Hassani MR, Chakir N, Jiddane M. Primary Ewing sarcoma of the skull vault [in French]. J Radiol 2007;88(12):1899-1901

2 Gadani S, Mody RP, Solanki RN, Mahajan A. Primary Ewing sarcoma on skull vault in a child. Ind J Radiol Imag 2003;13:303-305

3 Yih L, Windy YC. Taipei. Ewing's sarcoma of the hand. J Hand Surg Am 1998;23A:748-752

4 Dreyfuss UY, Auslander L, Bialik V, Fishman J. Ewing's sarcoma of the hand following recurrent trauma; a case report. Hand 1980;12(3):300-303
5 Özdemir N, Tektas S. The calvarial lesions. J Neurol Sci Turish 2004;21:57-75

6 Pritchard DJ, Dahlin DC, Dauphine RT, Taylor WF, Beabout JW. Ewing's sarcoma. A clinicopathological and statistical analysis of patients surviving five years or longer. J Bone Joint Surg Am 1975;57(1):10-16

7 Garg A, Ahmad FU, Suri A, et al. Primary Ewing's sarcoma of the occipital bone presenting as hydrocephalus and blindness. Pediatr Neurosurg 2007;43(2):170-173

8 Medina LS, Frawley K, Zurakowski D, Buttros D, DeGrauw AJ, Crone KR. Children with macrocrania: clinical and imaging predictors of disorders requiring surgery. AJNR Am J Neuroradiol 2001;22(3):564-570

9 Wang D, Guo Z. Multiple primary Ewing's sarcomas in cerebral cranium of a child: a case report and review of the literature. Int J Clin Exp Pathol 2015;8(6):7575-7582

10 Li WY, Brock P, Saunders DE. Imaging characteristics of primary cranial Ewing sarcoma. Pediatr Radiol 2005;35(6):612-618

11 Desai KI, Nadkarni TD, Goel A, Muzumdar DP, Naresh KN, Nair CN. Primary Ewing's sarcoma of the cranium. Neurosurgery 2000;46(1):62-68, discussion 68-69

12 Hadfield MG, Luo VY, Williams RL, Ward JD, Russo CP. Ewing's sarcoma of the skull in an infant. A case report and review. Pediatr Neurosurg 1996;25(2):100-104 